Most European patients would agree to change treatment to lower pain. Almost $82 \%$ stated they would accept rare adverse events in order to avoid invalidity, to confirm a better future outcome. US patients were more prone to stick to current therapy than escalade to increase clinical response. However, asked about novel therapies, Romanians were reluctant to changing treatment despite insufficient benefit, if the risk of cancer was noted. There was a high agreement that a delay in treatment would be unsatisfactory for both familial and professional chores. Conclusion: There are regional differences in knowledge and perceptions about RA treatment. Romanian patients know less on T2T algorithm. Improving awareness of the T2T strategy among RA patients may need different types of support depending on the patient's place of residence.

References:

[1] Smolen, J. S. et al. EULAR recommendations for the management of rheumatoid arthritis with synthetic and biological disease-modifying antirheumatic drugs: 2016 update. Ann. Rheum. Dis. 76, 960-977 (2017).

[2] Owensby, J. K. et al. Patient- and Rheumatologist- Perspectives Regarding Challenges to Achieving Optimal Disease Control in Rheumatoid Arthritis. Arthritis Care Res. (Hoboken). 0-2 (2019).

Disclosure of Interests: CLAUDIA COBILINSCHI Speakers bureau: novartis, Maria Danila Speakers bureau: as personally stated, Daniela Opris-Belinski Speakers bureau: as declared, Ioana Saulescu Speakers bureau: Eli-Lilly, Pfizer, Laura Groseanu Speakers bureau: novartis, eli-lilly, ucb, pfizer,sandoz, Sanziana Daia-Iliescu Speakers bureau: sandoz, Catalin Codreanu Consultant of: Speaker and consulting fees from AbbVie, Accord Healthcare, Alfasigma, Egis, Eli Lilly, Ewopharma, Genesis, Mylan, Novartis, Pfizer, Roche, Sandoz, UCB, Speakers bureau: Speaker and consulting fees from AbbVie, Accord Healthcare, Alfasigma, Egis, Eli Lilly, Ewopharma, Genesis, Mylan, Novartis, Pfizer, Roche, Sandoz, UCB, Razvan Ionescu Speakers bureau: as personally stated, Magda Parvu Consultant of: Speaker fee and consultant: Pfizer, Novartis, Roche, Abbvie, UCB, Eli-Lilly, Speakers bureau: Speaker fee and consultant: Pfizer, Novartis, Roche, Abbvie, UCB, Eli-Lilly, Horatiu Popoviciu Speakers bureau: as personally stated, CODRINA ANCUTA Consultant of: AbbVie, Pfizer, Roche, Novartis, UCB, Ewopharma, Merck Sharpe and Dohme, and Eli Lilly, Speakers bureau: AbbVie, Pfizer, Roche, Novartis, UCB, Ewopharma, Merck Sharpe and Dohme, and Eli Lilly, Elena Rezus: None declared, Claudia Mihailov Speakers bureau: as personally stated, Ruxandra Ionescu Consultant of: Consulting fees from Abbvie, Eli-Lilly, Novartis, Pfizer, Roche, Sandoz, Speakers bureau: Consulting and speaker fees from Abbvie, Eli-Lilly, Novartis, Pfizer, Roche, Sandoz DOI: 10.1136/annrheumdis-2020-eular.4747

\section{AB1270 RHEUMATOLOGY WORKFORCE IN LATIN AMERICA: TRAINING AND CURRENT STATUS}

D. G. Fernández-Ávila ${ }^{1}$, D. Patino-Hernandez ${ }^{1}$, S. Kowalski ${ }^{1}$, A. VargasCaselles $^{1}$, A. M. Sapag Durán ${ }^{1}$, A. Cachafeiro Vilar ${ }^{1}$, B. Meléndez ${ }^{1}$, C. S. Pastelín ${ }^{1}$, C. Graf ${ }^{1}$, C. Rossetto ${ }^{1}$, D. Palleiro ${ }^{1}$, D. Trincado ${ }^{1}$, D. FernándezÁvila $^{1}$, D. Arrieta ${ }^{1}$, G. Reyes ${ }^{1}$, J. Then ${ }^{1}$, M. F. Ugarte-Gil ${ }^{1}$, M. Cardiel ${ }^{1}$, N. Colman ${ }^{1}$, N. Chávez ${ }^{1}$, P. Burgos ${ }^{1}$, R. Montufar ${ }^{1}$, S. Sandino ${ }^{1}$, Y. FuentesSilva ${ }^{1}$, E. Soriano ${ }^{1} .{ }^{1} P A N L A R$, Miami(Headquarters), United States of America

Background: The demand for rheumatology care has been steadily increasing over the last few years. However, supply seems to be insufficient, according to previous research ${ }^{1}$. This situation may be at least partly explained by less physicians beginning a rheumatology residency program ${ }^{2}$.

Objectives: We aim to identify baseline data, room for change, and to strengthen functional processes associated with the rheumatology workforce in order to improve care offered to patients living with rheumatic diseases.

Methods: Descriptive cross-sectional study. We obtained data on each country through local PANLAR rheumatologists. They completed an online survey using the RedCap $®$ platform, used for capture and storage of data. The sample was described according to the type of variable.

Results: 19 Latin American countries were included in this study, globally 1 rheumatologist was available per 106,838 inhabitants. The highest rates were found in Uruguay (1 per 23.695 inhabitants) and Argentina (1 per 40.384 inhabitants). The lowest rates were found in Nicaragua (1 per 640.648 inhabitants) and Guatemala ( 1 per 559.902 inhabitants). The ratio between women and men rheumatologists was 0,99 women per each man. The lowest proportions were found in Peru $(0,26: 1)$, and the highest in the Dominican Republic (2.5:1). The average age for rheumatologists was 51,6 (SD12,75). Lowest average ages were found in Paraguay $(43,1$ SD10,77) and the highest age averages were found in Peru (56,23 SD12.93). The average monthly compensation was USD \$2.382,6 $(\mathrm{SD} \$ 1.462,5)$. Venezuela had the lowest salary $(\$ 197)$, the highest salary was found in Costa Rica (\$4.500). The proportion of rheumatologists trained abroad was $26,7 \%$, ranging between $0 \%$ in Uruguay and $90 \%$ in Bolivia.

The countries with more rheumatology training programs were Brazil $n=50$ and Mexico $n=20$, while Ecuador, Honduras and Nicaragua don't have any. The countries with the greatest amount of active residents were Brazil $(n=252)$ and Argentina $(n=100)$. The educational level required to enter the program was postgraduate studies in internal medicine in $42.11 \%$ of the programs. Currently, 108 residency programs in Latin America are active. Duration of residency programs is variable: 2 years $(79.63 \%$ of cases), 3 years $(16.67 \%), 4$ years $(1.85 \%)$ 5 years $(0.96 \%)$ or 6 years $(0.96 \%)$. The median monthly compensation for residents was \$ 528 USD (IQR \$ 774), the country with the highest payment was Costa Rica (\$2637). Contrarily, in Cuba, Chile and Colombia there is no payment to residents. Finally, in 8 countries $(42.11 \%)$ residents must not pay for their postgraduate studies, the average annual tuition expense in the rest of countries is \$ 1248 (SD \$2749).

Conclusion: The rate of rheumatologists per inhabitant is low. The demographic characteristics and the current status of the rheumatology workforce, as well as rheumatology training in Latin-America varies widely among countries. For instance, relevant differences can be found regarding payment to rheumatologists and residents, and tuition fees. The collected information will be useful when planning regional-based strategies, as well as for future research projects in each country and within PANLAR.

\section{References:}

[1] Battafarano DF, Ditmyer M, Bolster MB, et al. 2015 American College of Rheumatology Workforce Study: Supply and Demand Projections of Adult Rheumatology Workforce, 2015-2030. Arthritis Care Res.2018;70(4):617-26

[2] Zborovski S, Rohekar G, Rohekar S. Strategies to improve recruitment into rheumatology: results of the Workforce in Rheumatology Issues Study. J Rheumatol. 2010;37:1749-55

Disclosure of Interests: Daniel G. Fernández-Ávila: None declared, Daniela Patino-Hernandez: None declared, Sergio Kowalski: None declared, Alfredo Vargas-Caselles: None declared, Ana María Sapag Durán: None declared, Antonio Cachafeiro Vilar: None declared, Belia Meléndez: None declared, Carlos Santiago Pastelín: None declared, Cesar Graf: None declared, Chayanne Rossetto: None declared, Daniel Palleiro: None declared, Daniela Trincado: None declared, Diana Fernández-Ávila: None declared, Dina Arrieta: None declared, Gil Reyes: None declared, Jossiell Then: None declared, Manuel F. Ugarte-Gil Grant/ research support from: Jannsen, Pfizer, Mario Cardiel: None declared, Nelly Colman: None declared, Nilmo Chávez: None declared, Paula Burgos: None declared, Ruben Montufar: None declared, Sayonara Sandino: None declared, Yurilis Fuentes-Silva: None declared, Enrique Soriano Grant/research suppor from: AbbVie, Eli Lilly, GlaxoSmithKline, Novartis, Pfizer Inc, Sandoz, Consultant of: AbbVie, Eli Lilly, GlaxoSmithKline, Novartis, Pfizer Inc, Sandoz, Speakers bureau: AbbVie, Amber, Bristol-Myers Squibb, Eli Lilly, Novartis, Pfizer Inc, Roche DOI: 10.1136/annrheumdis-2020-eular.2353

\section{AB1271 \\ PATIENT EDUCATION IN PSORIATIC ARTHRITIS: A SERVICE EVALUATION AT ONE YEAR}

K. Austin ${ }^{1}$, R. Prasad ${ }^{1} .{ }^{1}$ University Hospitals Bristol NHS Foundation Trust, Rheumatology, Bristol, United Kingdom

Background: Recent studies have demonstrated an increasing burden of musculoskeletal (MSK) diseases worldwide. ${ }^{1}$ The importance of patient education $(P E)$ is often overlooked in the management of long term inflammatory conditions. The European League Against Rheumatism recommends that PE should be integral to standard of care in inflammatory arthritis. ${ }^{2}$ PE increases patients knowledge, skills and confidence in managing their condition and improves patient activation (PA). Evidence shows that improved PA results in better outcomes and improved experiences of care. We previously reported on improved knowledge and confidence amongst a small patient group with psoriatic arthritis (PsA) who had attended a pilot education session. ${ }^{3}$ This education session was delivered to a wider group of patients with PsA over a 12 month period; we report on the evaluation received from this service.

Objectives: To provide a PE programme to a wider group of patients with PsA using a multi-disciplinary team (MDT) approach and to evaluate whether this improved patients' knowledge, skills and confidence in managing their PsA.

Methods: Adult patients with PsA attending their rheumatology clinic appointments were invited to a 2.5 hour MDT education session which covered: 1) a general overview of PsA; 2) medications used in PsA; 3 ) the role of physiotherapy and occupational therapy; 4) flares and self- management. These were interactive sessions, held in a small group setting to allow for informal discussion and questions to the MDT. Written materials including several booklets and online resources were also provided. Patients evaluated their knowledge or understanding before and after each topic covered, on the same day, using an evaluation tool with1-10 Likert scale items. Changes in ratings were analysed using student's t-tests. Patients were also asked: which aspects they found particularly helpful; if there was anything they would like to have added/ have more of in the session; whether they found the session helpful; whether they would recommend 
it to other patients; whether they would be interested in developing a PsA patient support group.

Results: Four sessions were held over a 12 month period. A total of 32 patients attended; 10 males and 22 females, across a range of age categories. Disease duration varied from less than 1 year to over 10 years. There were statistically significant improvements in all topics covered: mean improvement of $91 \%$ in how well informed patients felt about PsA overall $(p<0.0001)$; mean improvement of $74 \%$ in confidence in accessing help from the MDT $(p<0.0001)$; mean improvement of $122 \%$ in how well informed patients were about medications used in PsA ( $p<0.0001$ ); mean improvement of $99 \%$ in patients' confidence in self-managing a flare $(p<0.0001)$. Aspects that patients found particularly helpful included "The whole session", "Asking questions to all different professionals", "Meeting other sufferers", "Management of flares", "Fatigue information" and "Online resources". Overall, $97 \%$ of patients (31 out of 32 ) found the session helpful and would recommend it to others. Over $40 \%$ of patients expressed interest in developing a local PsA support group.

Conclusion: Following a 2.5 hour education session, improved knowledge, skills and confidence in managing their PsA was reported by $97 \%$ of patients, including patients with disease duration of $>10$ years. This supports our previous finding that an interactive, group PsA education programme is a feasible and important adjunct to patient care.

References:

[1] Sebbag E, Felten R, Sagez F, et al. The world-wide burden of musculoskeletal diseases: a systematic analysis of the World Health Organization Burden of Diseases Database. Annals of the Rheumatic Diseases 2019;78:844-848.

[2] Zangi HA, Ndosi M, Adams J, et al. EULAR recommendations for patient education for people with inflammatory arthritis. Ann Rheum Dis. 2015;74(6):954-62

[3] Austin K, Jones N, Prasad R. Patient Education in psoriatic arthritis: addressing an unmet need. Ann Rheum Dis. 2019;78(suppl 2):A2134

Disclosure of Interests: Keziah Austin: None declared, Roopa Prasad Speakers bureau: Received speaker fees for Celgene, honorarium from Merck, advisory board fees from Bristol-Myers Squibb; all unrelated to the contents of this abstract.

DOI: 10.1136/annrheumdis-2020-eular.5032

\section{$\mathrm{AB} 1272$ \\ ONLINE EDUCATION BOOSTS CLINICIAN KNOWLEDGE ABOUT EMERGING THERAPIES FOR PATIENTS WITH SYSTEMIC SCLEROSIS-ASSOCIATED INTERSTITIAL LUNG DISEASE}

C. Rohani-Montez ${ }^{1,2}$, M. Calle ${ }^{1,2}$, C. Allen ${ }^{1,2}$, A. M. Hoffmann-Vold ${ }^{3}$, O. Distler ${ }^{4}$. ${ }^{1}$ Medscape Education Global, London, United Kingdom; ${ }^{2}$ WebMD, New York, United States of America; ${ }^{3}$ Oslo University Hospital, Oslo, Norway; ${ }^{4}$ University Hospital of Zürich, Zürich, Switzerland

Background: Systemic sclerosis-associated interstitial lung disease (SSc-ILD) has traditionally been treated with therapies such as cyclophosphamide, mycophenolate mofetil, and hematopoietic stem cell transplantation. However, these therapies are limited by potential toxicity, as well as duration and magnitude of effect. Clinicians need awareness of emerging therapies in late-stage clinical trials that may address these limitations.

Objectives: This study was conducted to determine whether online independent medical education could improve rheumatologists' and pulmonologists' knowledge of emerging therapies for the management of SSc-ILD.

Methods: Physicians ( $N=2,076)$ participated in a 30-minute, 2-faculty, video-based, online CME with synchronized slides. ${ }^{1}$ The majority of participants were rheumatologists ( $n=522$ ) or pulmonologists $(n=557)$, but the cohort also included clinical immunologists $(n=132)$ and other physicians with an interest in the topic $(n=865)$. This study focuses on the 120 rheumatologists and 111 pulmonologists who completed all pre- and post-questions. The effects of the education on knowledge was assessed using a 3-question, repeated pairs, pre-assessment/post-assessment study design. For all questions combined, the chi-square test assessed differences from pre- to post-assessment. $P$ values $<.05$ are statistically significant. The activity launched on September 17, 2019, and data were collected through November 5, 2019.

Results: Overall significant improvements were seen after participation for both rheumatologists (average correct response rate of $55 \%$ at pre-assessment vs $75 \%$ at post-assessment; $\mathrm{P}<.001, \mathrm{~N}=120$ ), and pulmonologists (average correct response rate of $60 \%$ at pre-assessment vs $77 \%$ at post-assessment; $\mathrm{P}<.001$, $\mathrm{N}=111$ ). Specifically, significant improvements were observed in clinicians' knowledge of clinical trial data for emerging SSc-ILD therapies (figure).

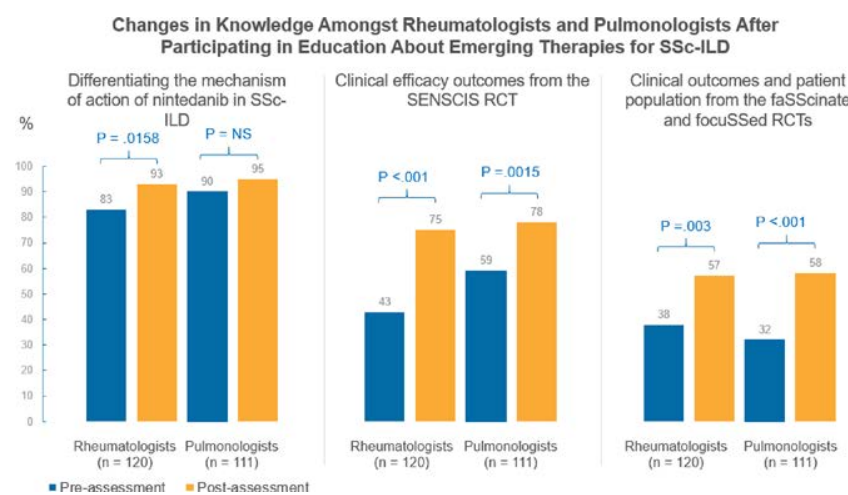

Figure.

Clinicians from APAC $(n=67)$ and Europe $(n=79)$ made up the majority of the cohort, and had similar rates of correct responses without significant differences, indicating consistent effects, independent of the region of origin. After participating in the activity, $48 \%$ of pulmonologists and rheumatologists had measurable improved confidence related to their knowledge of emerging therapies for patients with SSc-ILD.

Despite the increases in knowledge and confidence observed, the rates of correct responses suggest there is still room for improvement; therefore, ongoing education will be needed to reinforce knowledge of the latest data evaluating new therapies for SSc-ILD and what they will mean for future practice.

Conclusion: This study demonstrates the success of online, video-based education in improving rheumatologists' and pulmonologists' knowledge of the latest clinical data on emerging therapies for SSc-ILD. This could lead to earlier adoption of new, efficacious therapies that may slow disease progression and improve overall outcomes for these patients.

References:

[1] Distler O, Hoffmann-Vold A-M. How Can We Meet the Treatment Needs of Patients With Systemic Sclerosis-Interstitial Lung Disease? Launched: 9/17/2019. Data as of 11/5/2019. Available at www.medscape.org/ viewarticle/917034

Disclosure of Interests: Christy Rohani-Montez: None declared, Marinella Calle: None declared, Chris Allen: None declared, Anna-Maria Hoffmann-Vold Grant/ research support from: Boehringer Ingelheim, Consultant of: Boehringer Ingelheim, Actelion, Bayer, GlaxoSmithKline, Speakers bureau: Boehringer Ingelheim, Actelion, Roche, Oliver Distler Grant/research support from: Grants/Research support from Actelion, Bayer, Boehringer Ingelheim, Competitive Drug Development International Ltd. and Mitsubishi Tanabe; he also holds the issued Patent on mir-29 for the treatment of systemic sclerosis (US8247389, EP2331143)., Consultant of: Consultancy fees from Actelion, Acceleron Pharma, AnaMar, Bayer, Baecon Discovery, Blade Therapeutics, Boehringer, CSL Behring, Catenion, ChemomAb, Curzion Pharmaceuticals, Ergonex, Galapagos NV, GSK, Glenmark Pharmaceuticals, Inventiva, Italfarmaco, iQvia, medac, Medscape, Mitsubishi Tanabe Pharma, MSD, Roche, Sanofi and UCB, Speakers bureau: Speaker fees from Actelion, Bayer, Boehringer Ingelheim, Medscape, Pfizer and Roche

DOI: 10.1136/annrheumdis-2020-eular.457

\section{AB1273 TEACHING RARE DISEASES THROUGH ROLE PLAY: RESULTS OF AN EXPERIMENTAL WORKSHOP ON RAYNAUD PHENOMENON}

S. Sanges $^{1,2,3,4}$, S. Morell-Dubois ${ }^{2,4}$, M. M. Farhat ${ }^{1,2,4}$,

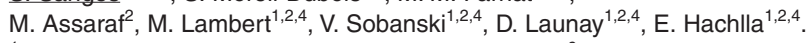

${ }^{1}$ Université Lille, Faculté de Médecine, Lille, France; ${ }^{2} \mathrm{CHU}$ Lille, Service de Médecine Interne, Lille, France; ${ }^{3}$ Centre de Simulation PRESAGE, Lille, France;

${ }^{4}$ Centre National de Référence Maladies Systémiques et Auto-immunes Rares

(Sclérodermie Systémique), Lille, France

Background: Systemic autoimmune diseases are mostly taught through theoretical lectures, which do not allow for the acquisition of physical examination skills and semiologic confrontation.

Objectives: We report herein the results of a pilot experiment using role-play to teach how to manage patients with Raynaud phenomenon (RP).

Methods: We developed a workshop that consisted of two 30-minute OSCE (Objective and Structured Clinical Examination) stations. Students were divided into groups of 4 to 5 persons. On each station, 2 students were actors and 2 were observers. After a short briefing, students played a 15-minute scenario and then had a 15-minute debriefing.

The first station simulated the case of a 26-year old woman referred for suspected RP. Students were instructed to perform clinical history taking and 